\title{
EL ŠAYH ESTÁ RODEADO DE ÁNGELES Y GENIOS. UN ESTUDIO SOBRE LOS SERES INTERMEDIALES EN EL SUFISMO PULAR
}

\section{Antonio de Diego González}

Enviado: 3/01/2019. Aceptado: 6/03/2019.

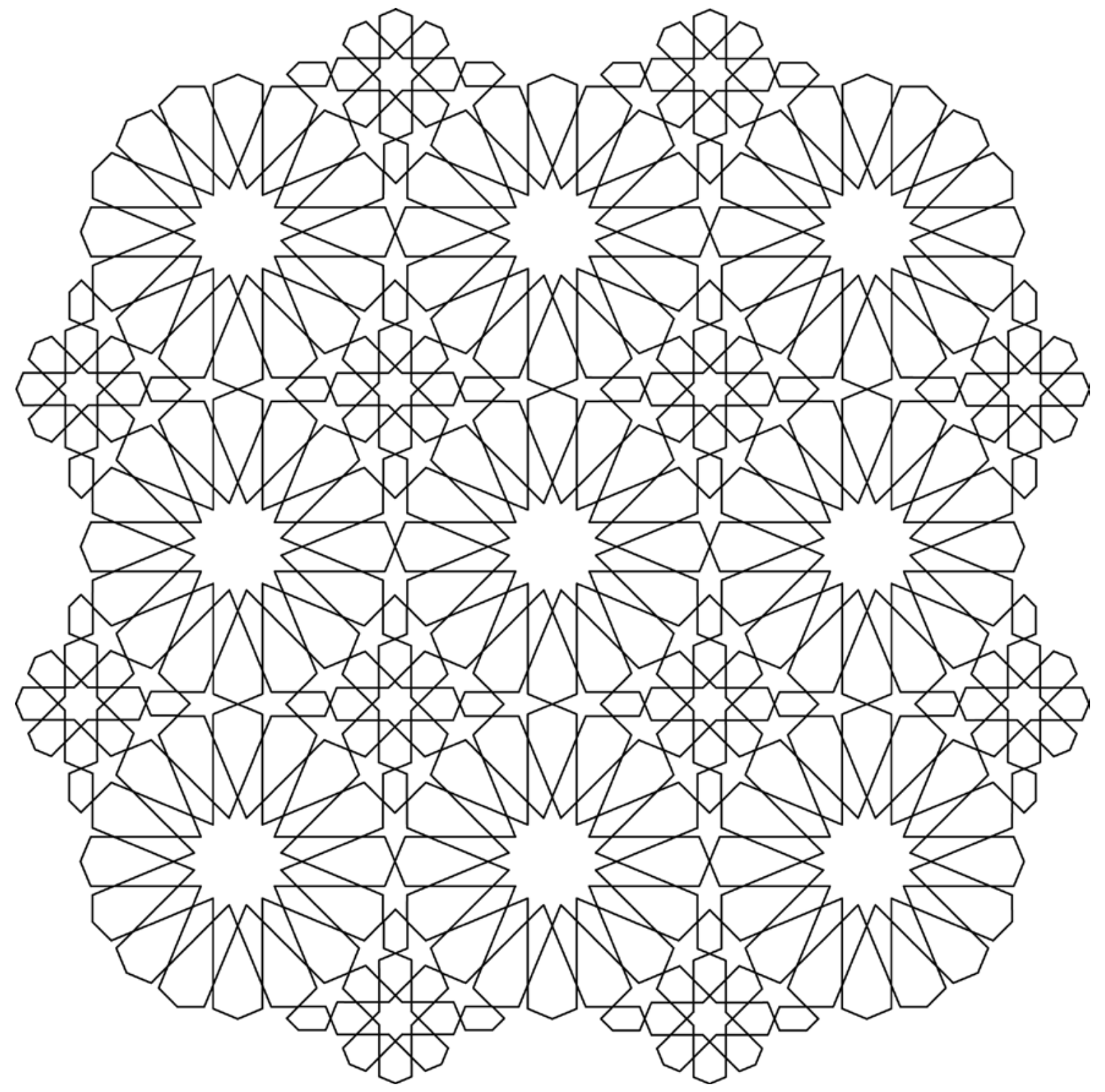


Resumen: El sufismo del Sahel posee una gran riqueza simbólica. Las elaboradas cosmologías del sufismo akbariano, en el que se inspira el neo-sufismo, se entremezclan con tradiciones milenarias donde el genio (ğinn) y el ángel (malak) conviven con los humanos como otrora lo hacían los espíritus naturales y los ancestros. Este texto esboza, desde el trabajo de campo y las fuentes escritas, una aproximación a una lectura simbólica de las relaciones entre humanos, ángeles y genios en el sufismo de la etnia pular y, en concreto, en la experiencia y la narrativa del maestro sufí senegalés Thierno Hassan Dem.

Palabras clave: Sufismo, Sahel, Angelología, Talismán, Pular, Tiğāniyya.

Abstract: The Sufism of the Sahel has a great symbolic richness. The elaborate cosmologies of Akbarian Sufism, in which neo-Sufism is inspired, are interspersed with millenary traditions where the genius (ğinn) and the angel (malak) coexist with humans as once the natural spirits and ancestors did. This paper outlines, from the fieldwork and the written sources, an approach to a symbolic reading of the relations between humans, angels and geniuses in the Sufism of the Fulani people. This study focuses, mainly, in the experience and narratives of the Senegalese Sufi master Thierno Hassan Dem.

Keyword: Sufism, Sahel, Angelology, Talisman, Fulani, Tiǧāniyya.

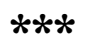

\section{INTRODUGGIÓN}

El sufismo del Sahel posee una gran riqueza simbólica. Las elaboradas cosmologías del sufismo akbariano, en el que se inspira el neo-sufismol, se entremezclan con tradiciones milena-

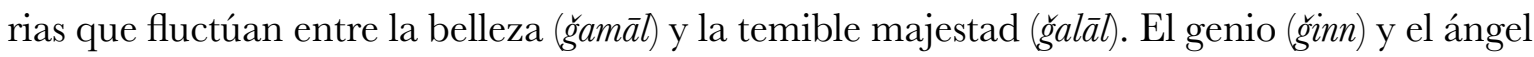
(malak) conviven con los humanos como otrora lo hacían los espíritus naturales y los ancestros de los pueblos indígenas africanos. Dos figuras centrales que, aún a día de hoy, tienen un peso extraordinario en los imaginarios locales.

El genio y el ángel constituyen dos categorías básicas para la vida espiritual y social en el Sahel. Dos categorías de poder con las que operan los musulmanes de la región. Ángeles

1 El primer autor académico que usó este término fue el filósofo norteamericano de origen pakistaní Fazlur Rahman, para describir el cambio de mentalidad que se había producido ciertas tarīqas en los siglos XVIII y XIX, diferenciándose de las țarīqas clásicas, especialmente, las que los otomanos dominaban política y espiritualmente, tomando como base la cosmología akbariana y el uso exhaustivo del hadìith. El concepto en sí ha sido ampliamente discutido y ampliado por Nehemia Levtzion y John Voll además de Bernd Radtke y Rex. S. O’Fahey. 
que protegen y genios que se islamizan o que prosiguen en las creencias de sus antepasados. Durante mi trabajo de campo en la región fui testigo de muchas de estas narraciones que son recitadas con gran vehemencia por multitud de personas, que se plasman en papel como talismanes o que se ejecutan como rituales de exorcismo o de pacto.

Si algo hay que clarificar es que estas prácticas en ningún caso pertenecen, exclusivamente, a una versión popular del islam como algunos sociólogos de la religión han dejado entrever. Estas creencias o narrativas están en todos los niveles del islam tradicional, es decir, el sufismo que practican amparados en una tradición pre-moderna y pre-colonial. Los diferentes caminos (tariqa) sufíes las han adoptado como algo que es connatural a sus praxis. No obstante, el Corán y la sunna (tradición profética) afirman las experiencias con genios y ángeles, y la 'aqīda (teología) mayoritaria obliga a la creencia en estos seres. De ahí que un docto šayh (maestro) sufí no tenga problema no solo en creer, sino en tratar con ellos e incluso darles clases de Corán, de fiqh (jurisprudencia islámica) o de sufismo.

Esta es la premisa de este texto, mostrar como los genios y ángeles en el Sahel conviven con los hombres actuando en un «interplano cosmológico», haciendo comprensivo y tangible un mundo intermedial del que se puede beneficiar los creyentes. Así, la metafísica se hace realidad y deja de ser palabras de libros medievales para convertirse en algo útil para la comunidad. Esta convivencia e interacción -según me explicaba un informante de la etnia pular- no deja de ser parte de la vía del Profeta (tarīqa muhammadiyya) y una forma de reiterar su ejemplo en nuestro mundo. ${ }^{2}$

Como podemos ver las lógicas racionales saltan por los aires, mientras que la tradición y la metafísica se reafirman en culturas que las necesitan para sobrevivir en un mundo asediado por el materialismo, el islamismo político y el salafismo. Estas ideologías tienden a demonizar y despreciar prácticas metafísicas de gran arraigo que son terapéuticas (en el sentido más profundo de la palabra) para la comunidad. Se desvirtúa el valor de lo esotérico (bātin). El šayh se convierte en el último guardián del conocimiento de los ancestros, en el guardián del acceso a otros planos de la realidad que guardan una valiosa gnosis (ma'rifa) de la auténtica realidad (haqq bi-l-haqq).

El islam llegó a África Subsahariana muy pronto y no tuvo grandes problemas para adaptarse a la realidad en la que se asentó. Como ocurrió en otros lugares islamizados. Esto es algo que ya expliqué anteriormente en el libro Sufismo Negro:

Así, debemos señalar que, aunque el concepto de sufismo estuvo presente desde el principio de la islamización, no nos es posible trazar su influencia

2 Notas de trabajo de campo en Kaolack, Senegal, julio de 2016. 
histórica hasta el establecimiento de las tarīqas, que se reflejan a través de fuentes textuales u orales. Podríamos hablar de un sufismo de carácter informal, frente a un sufismo formal fundamentado en la estructura de las tarīqas, en los primeros siglos del África islámica. Este sufismo procede de los ermitaños magrebíes (murābit), de los sabios tuareg (ineslaman) y de las tribus beréberes mauritanas (zawāyas) que reclamaban para sí ser descendientes del Profeta Muhammad. Todos ellos realizaron incursiones a África subsahariana por motivos económicos o culturales, y erigidos como sabios, empezaron a ser respetados como los garantes del conocimiento tras perder poder político en sus tierras. Ese conocimiento que tenían, además, conllevaba una marcada autoridad social. Poco a poco todo esto empezó a determinar realidades concretas, primero en el Sahel y después en toda África Occidental. Y, se establecieron como élites intelectuales y sociales. ${ }^{3}$

De esta forma, los indígenas del Sahel comprendieron que el islam, aunque siendo una práctica exógena, respondía a sus necesidades. Pues el islam no rechazaba las creencias y cosmovisiones anteriores, sino que las islamizaba incorporándolas a su realidad como ya había hecho en otros territorios. Los sabios tradicionales también se islamizaron y comenzaron a compartir con los musulmanes todo tipo de conocimientos entre los que se encontraban las tecnologías de protección ${ }^{4}$ Así hausas, pulares, wolof o madinké ponían sus conocimientos tradicionales al servicio del islam, y este le ponía etiquetas, comprensibles allende sus fronteras, y justificaba los seres y fenómenos que existían en la región.

En un ecosistema espiritual tan agresivo espiritualmente como el saheliano, donde los brujos y brujas son algo habitual, estos conocimientos eran (y siguen siéndolo aún hoy), de gran valor. A los recursos tradicionales ${ }^{5}$, heredados de sus cosmovisiones propias, se le añadió todo el conocimiento esotérico que con el tiempo llegaba de los intercambios culturales. El hağğ llevó a África Subsahariano conocimiento de diverso tipo entre ello el esoterismo akbariano y šarqī que aparece en diversos autores del sufismo africano como šayh al-Fūti Tāl (1794-1865) o Ibrāhīm Niasse (1900-1975). Así, las diferentes vías sufies africanas terminaron de dar forma a este conocimiento y a su interrelación con la realidad formando una rica amalgama de tradiciones étnicas y conocimiento islámico.

3 Antonio de Diego González, Sufismo Negro, Córdoba, Almuzara, 2019, p. 37

4 ibid., p. 38; Zachary Wright, Living Knowledge in West African Islam, Leiden, Brill, 2015, pp. 48-51

5 Mariko Namba Walter y Eva Jane Neumann, Shamanism, An Encyclopedia of World Beliefs, Practices and Culture, Santa Barbara, ABC Clio, 2004, pp. 930-934. 
De entre todas ellas destaca la Tiğāniyya, fundada por el šayh Aḥmad al-Tiğānī (1735-1815) cuya vocación akbariana es notoria. ${ }^{6}$ Durante el siglo XIX esta tarīqa se expandió por toda África auspiciada por su doctrina de $\check{s}^{2} \bar{r}^{-} a$ wa-haqūqa, es decir, de la convivencia entre el plano exotérico y lo esotérico. A diferencia del salafismo y el islamismo, el sufismo de la Tiğāniyya facilitaba no solo la práctica esotérica, sino que la defendía dentro de la ortodoxia y como parte de la tradición del Profeta Muhammad. De hecho, y a día de hoy, este es un debate que los tiğāníes siguen manteniendo y que diversos investigadores se han hecho eco contradiciendo las opiniones negativas de los islamistas y los salafistas ${ }^{7}$ En el fondo subyace un enfrentamiento sobre un pretendido racionalismo formalista (salafismo) y una experiencia social transcendental personal y grupal. Un hecho colectivo que, a su vez y por ser esotérica, es controlada y guiada por un šayh, la persona autorizada para realizarlo.

Es desde este marco del que parte el texto. Como ya he mencionado, el núcleo del estudio está elaborado desde las notas de un trabajo de campo realizado en el mes de Julio de 2016 en Senegal en torno a uno de los líderes sufies más carismáticos de la región: Thierno Hassan $\operatorname{Dem}(1920-1989)$.

El primer objetivo de este texto es mostrar, desde una perspectiva hermenéutica, como aún se mantienen vivas, en la actualidad, narrativas angelológicas y demonólogicas en la región del Sahel. El segundo objetivo es ver cómo han influido las propias visiones étnicas - en este caso de los pulares- sobre las sufies, amalgamándose y aumentando la riqueza de las cosmovisiones. $\mathrm{Y}$, por último, mi intención es ver como todo lo anterior se manifiesta ejemplos concretos tanto en narraciones orales hagiográficas como en tecnología de protección (talismanes).

\section{LA SABIDURÍA ESOTÉRIGA DE LOS PULARES}

Los pulares, también conocidos como fulanis, son uno de los mayores grupos étnicos de África y uno de los mayores grupos nómadas del mundo. Diseminados a lo largo y ancho del Sahel, se extienden desde Mauritania hasta República Centro Africana. Su origen es desconocido, aunque autores como Cheikh Anta Diop lo han localizado en Egipto. ${ }^{8}$ Se islamizaron en el siglo $\mathrm{XV}$, aunque nunca terminaron de rechazar sus tradiciones cosmológicas ni epistemológicas.

6 Antonio de Diego González, Identidades y modelos de pensamiento en África, Tesis Doctoral, Sevilla, Universidad de Sevilla, p. 315.

7 Véase el trabajo del investigador alemán Rudiger Seesemann donde duda de los conceptos de ortodoxia y heterodoxia con respecto al islam y de forma particular con el sufismo en África Occidental. Su argumento de base es que los tiğānis son un grupo ortodoxo, aunque practiquen un marcado esoterismo. Rudiger Seesemann, The Divine Flood, Londres, Oxford University Press, 2011. 8 Cheikh Anta Diop, The African origin of civilization: myth or reality. New York, L. Hill, 1974. pp. 155-191 
Los pulares fueron una de las etnias clave para el desarrollo del Sahel pre-moderno junto con los wolof y los hausa, y su construcción como territorio islámico. Su islamización les convirtió de pastores trashumantes en una clase social especializada en el conocimiento religioso tanto exotérico como esotérico. ${ }^{9}$ Los pulares se hicieron grandes especialistas en el Corán y en el Sufismo. Su cenit llegó con el posicionamiento de 'Utumān Dan Fodio ${ }^{10}$ (1754-1817) como califa de Sokoto a comienzos del XIX tras un proceso de ǧihād. Dan Fodio representa la quintaesencia de la comunidad pular en tanto sufí como líder político.

Las narrativas orales y tradicionales entre la propia etnia pular describen el uso de prácticas esotéricas y genios primero durante el ǧi $h \bar{a} d$ de Dan Fodio en la actual Nigeria y, posteriormente, durante el de Fūti Tāl unos años después en la actual Mali. ${ }^{11}$ En ellas se destaca como a sus ejércitos se les sumaban filas de genios islamizados que hacían rendirse a sus oponentes usando sus poderes esotéricos y sin usar mayor coacción que el terror que provocaban. En concreto los hechos relativos al šayh Fūti Tāl están recogidos, editados y traducidos del pular al inglés. Merece la pena resaltar este fragmento:

«10. One day, he waited until late at night, when people were sleeping. / He got up, he went to the chief of the Jinns. / The chief of the Jinns told him: / "Now I decided to give you an army, the army has come. / He gave him what must have been 100.000 jinns together with their guns. (...). 13. Shayku Umar left in the morning, he left with his army / What the people saw was only his army of men, / they did not see the army of jinns $(\ldots) » .^{12}$

El fragmento define una narrativa muy poderosa, la conjunción entre poder terrenal (sari $\left.{ }^{-} a\right)$ y poder esotérico (haqūqa). El šay̧h Fūti Tāl a través de sus conocimientos esotéricos fue capaz de reclutar genios musulmanes para que le ayudasen en la batalla desafiando a los gobernantes de los territorios cercanos que no le reconocen como el líder que el reclama ser. Parte de esta legitimidad se la otorgaba el esoterismo vía su herencia pular que es la que, junto con el designio de califa de šayh Tiğàn̄i, ${ }^{13}$ hacía de él un líder nato en lo exotérico y lo esotérico.

9 Ousmane Kane, Beyond Timbuktu, Cambridge, Harvard University Press, 2016, p. 71.

10 Antonio de Diego González, Sufismo Negro, Córdoba, Almuzara, 2019, pp. 45-46.

11 Notas de trabajo de campo en Kaolack, Senegal, julio de 2016.

12 Cf. en Moustapha Kane and David Robinson, The Islamic Regime of Futta Tooro: An Anthology of Oral Tradition Transcribed in Pulaar and Translated into English. African Studies Center, Michigan State University, 1984, pp. 123-127.

13 Antonio de Diego González, Sufismo Negro, Córdoba, Almuzara, 2019, pp. 85-90. 
De hecho, y aún hoy en día, en la región del Sahel los cuadernos de secretos (kunnāš al-asrār) más codiciados son los escritos por los autores pulares. Porque son los que contienen los secretos más poderosos según los sabios tradicionales de la región. ${ }^{14} \mathrm{Y}$, paradójicamente, todas estas prácticas se mantuvieron en el máximo secreto, censurando cualquier información que pueda quitarle un aura de estricta visión de guardianes de la aparente ortodoxia islámica.

Estas narrativas están aún vivas entre los pueblos rivales de los pular quienes ven en ellos grandes especialistas en lo oculto y, en particular, grandes negociadores con los genios islamizados o no. Esto les convertía en temibles y poderosos enemigos tanto en la batalla como en el día a día. Es por ello que, especialmente en los imaginarios de sus vecinos, a los pulares se les asocia con brujos o con colonizadores y se les envuelve en un halo de desconfianza, tal y como me decía un informante de etnia wolof: «No te fíes de un pular, no son ni blancos ni negros. Son amigos de los genios y viven entre sombras». ${ }^{15}$

Gran parte de este conocimiento proviene, precisamente, de su propia cosmología tradicional y de préstamos de los cultos de sus vecinos como los zarma o los hausa. Como ha mostrado Laurent Vidal $^{16}$, los peul han heredado un interesante sistema de rituales a espíritus tradicionales que identifican con los genios. Con una estructura similar a los cultos de los bóórí hausa o a los zär de Sudán ${ }^{17}$, el pueblo pular entiende que hay que negociar y someter a estos espíritus hasta convertirlos o doblegarlos. Y que esta acción puede acabar siendo de gran valor pues pueden transformarse en grandes aliados o en efectivos sirvientes. Vidal cita una carta del célebre antropólogo francés Gilbert Viellard en la que explícitamente cita un griot (narrador tradicional), quien explica cómo estos cultos representan una lucha entre «(...) la noche y el día, donde uno es aliado del crepúsculo y otro de la aurora». ${ }^{18}$

Una lucha en los mundos intermedios en los que el ser humano con cierta sensibilidad es capaz de percibir. Pues en el imaginario colectivo estos son tiempos de tránsito, de visiones de luz y sombra. Así, los espíritus, ángeles y genios luchan por el «cosmos» del mundo frente al ser humano que, una vez iniciado en el mundo esotérico tradicional o de la tarīqa sufí, les desafía haciendo prevalecer el poder de Adam. Si bien lo diabólico, de por sí, no es una categoría operante, sí lo es el poder de controlar, en nombre de Allāh, la realidad. Un control sobre

14 Notas de trabajo de campo en Kaolack, Senegal, julio de 2016.

15 Notas de trabajo de campo en Dakar, Senegal, julio de 2016.

16 Laurent Vidal, "La Possession par les génies chez les Peuls (Niger): De la parole a l'invention du rituel", Archives de sciences sociales des religions, 37e Année, No. 79 (1992), pp. 69-85

17 Antonio de Diego González, Identidades y modelos de pensamiento en África, Tesis Doctoral, Sevilla, Universidad de Sevilla, p. 50.

18 Cit. En Laurent Vidal, "Les génies et les hommes: les apports du fonds Gilbert Vieillard à l'histoire et à l'anthropologie de la possession rituelle en pays peul au Niger." Gradhiva 12 (1992), p. 26 
fenómenos y acciones en otros planos que hace que el iniciado pueda disolverse ( $f a n \vec{a})$ tras la comprensión de la esencia de la realidad (haqĩqa) al ser consciente de que, en el fondo, esa lucha entre fuerzas pertenece a una unidad, está en el dictado de Allāh. Y en esa pertenencia, el iniciado, y posteriormente disuelto, puede operar en la auténtica realidad (haqĩqa).

En mi opinión lo más interesante de la narración que recoge Viellard es que esta visión aún pervive en la región. De hecho, se entrelaza con un dicho que recogí, precisamente, de un anciano šayh pular (que prefirió conservar su anonimato) y que me aseveró en francés en una conversación sobre el papel de los genios (ğununn): «iSabes que la luna llena y el sol iluminan? Ángeles y genios aparentemente luchan, pero dependen de la misma luz: la del Profeta Muhammad». ${ }^{19}$ Este punto no solo vendría a corroborar lo que el viejo griot contó a Viellard, sino que añadiría una visión propia de la cosmología tiğānī tal y como había explicado y justificado en el Kitāb Rimāh del šạh al-Fūti Tāl con gran influencia cosmológica de Ibn 'Arabī. ${ }^{20}$

\section{“SABES QUE LA LUNA LLENA Y EL SOL ILUMINAN?»}

Ángeles y genios comparten un mundo común. Como ya he mencionado, y según la creencia de los habitantes del Sahel, estos seres viven en otros planos de realidad (haqũqa). Tanto ángeles como genios son mensajeros, transmisores y mediadores de conocimiento y gnosis. Operando desde un plano oculto (gayb), en mundos intermedios, y revelándose a aquellos dispuestos a escuchar.

Los ángeles (malāìka) son descritos en el Sahel, en consonancia con la tradición islámica, como seres benéficos para los creyentes y terribles para los no-creyentes. Seres que representan la pura voluntad de Allāh y que, normalmente, no son accesibles pues solo un šayh que esté en una posición (maqām) muy alta es capaz de tener contacto con ellos. Es una protección ante un conocimiento complejo y no comprensible para el resto de las personas. Esto aparece refrendado por šayh al-Dabbāg - uno de los pensadores claves del siglo XVIII en Áfricaquien en su libro al-Ibriz indica que los ángeles hablan en siriaco y son visibles por los santos $\left(\right.$ awliy $\left.\bar{a}^{\prime}\right) .{ }^{21}$ Sin embargo, si que están en la vida del creyente. También se les atribuye la

19 Notas de trabajo de campo en Kaolack, Senegal, julio de 2016.

20 Para este aspecto véase la fuente original en el Kitāb Rimāh II, pp. 16-23 y el comentario que realicé en Antonio de Diego González, Identidades y modelos de pensamiento en África, Tesis Doctoral, Sevilla, Universidad de Sevilla, pp. 338-344.

21 Véase las apreciaciones de šayh al-Dabbagh al respecto en en el comentario esotérico al Dĩwān 
protección a los niños y a los ancianos, la recogida de las almas de los fallecidos y, además, la gente les percibe, popularmente, con un frío que invade la mezquita o la estancia donde se hace $\underline{d i k r}$. La misma tradición islámica indica que son luz pura y, ante eso, mi informante añadía a esta explicación: «tienen el brillo del sol, son los rallos de la luz muhammadí (nūr muhammadiyya)». ${ }^{22}$ Por ello, el griot entrevistado por Veillard lo relacionaba con la aurora. Ellos traen el dictado de Allāh, un nuevo amanecer para el creyente.

Por su parte, los genios (ğunūn) son espíritus ígneos e invisibles tal y como el Corán los describe. ${ }^{23}$ Se trata de seres volubles que actúan con conciencia y por interés propio, como los seres humanos, y que pueden ser musulmanes o no, e incluso inclinarse a tendencias diabólicas. Esto es muy importante dentro de la propia tradición del Sahel, y en general del mundo islámico pre-moderno, porque con los genios musulmanes se pacta, mientras que a los no musulmanes se les somete mediante rituales esotéricos. ${ }^{24} \mathrm{El}$ šayh, especializado en estos temas, realiza los pactos necesarios para que los genios no se conviertan en seres revoltosos y molestos para la comunidad. Tradicionalmente, el carácter caprichoso y voluble de los genios les ha conferido ser seres de oscuridad y cuyo momento es la hora atardecer (magrib). Por ello, el griot antes mencionado lo relacionaba con el ocaso y la posterior noche. Sin embargo, mi informante me explicaba que tras ellos la noche nunca está oscura porque la luna y su luz, que no deja de ser simbólicamente luz muhammadiana (nūr muhammadiyya), ilumina igualmente ya que son seres que provienen de Allāh. ${ }^{25}$

Y al igual que hay un šayh que somete a los genios, también hay brujos que pueden realizar pactos para agredir a otras personas de la comunidad o para interés propio. Esta brujería es la que la ley islámica $\left(\check{s}^{2} a \bar{r}^{-} a\right)$ persigue y castiga porque estaría fuera del uso consciente de la realidad, al final se trataría de un pacto diabólico. El asunto se convierte en un dilema moral para con la propia praxis esotérica del islam.

El mundo en el que habitan ambos seres es el mundo de la intermedialidad entre el plano divino (hadra ilahīya) y el plano humano (hadra insāniyya), si bien realizan incursiones a la tierra. Esto era lo que Viellard citando el griot consideraba como «combate celeste». ${ }^{26} \mathrm{Y}$ es que solo

al-șäliḥ̄n (El consejo de los virtuosos). Aḥmad b. al-Mubārak al-Lamṭī, al-Dַahab al-ibrīz min kalām sayyidi 'Abdal'azīz al-Dabbāgh [Pure gold from the words of sayyidi'Abdal'azizz al-Dabbāgh]. Ed. y trad. Bernd Radtke y John O'Kane. Brill, Leiden, 2007, pp. 590-592.

22 Notas de trabajo de campo en Kaolack, Senegal, julio de 2016.

23 Corán, 15:26-27.

24 Zachary Wright, Living Knowledge in West African Islam, Leiden, Brill, 2015, p. 232.

25 Notas de trabajo de campo en Kaolack, Senegal, julio de 2016.

26 Cit. En Laurent Vidal, "Les génies et les hommes: les apports du fonds Gilbert Vieillard à l'histoire et à l'anthropologie de la possession rituelle en pays peul au Niger.” Gradhiva 12 (1992), p. 26 
aquel que emprende el sayr (viaje místico) es capaz de descifrar que todo son manifestaciones aparentes de una realidad que Allāh esconde. El sufi, ya iniciado, es capaz de desvelar lo simbólico y discernir lo aparente de lo ficticio, tranquilizando al que no lo consigue percibir o incluso enseñar a estos los genios para convivir con nosotros.

El sufismo, y más entendido desde la experiencia tiğānī, es ese desvelar lo aparente y quedare con la esencia con lo cual los seres interplanos serían manifestaciones que pueden deslumbrar al ser humano lo mismo que lo hace la luz del sol. En la conversación con mi informante me advertía que «mirar fijamente a una luz ciega... obsesionarse por esos seres te «rapta» (mağdūb) de la vida y te vuelve loco (mağnūn)». Esta situación es el arrebatamiento que los tiğāníes denuncian y que imposibilita para seguir una correcta educación espiritual (tarbiya) dentro de la tarīqa. ${ }^{27} \mathrm{Al}$ magnificar otras realidades, en concreto la de los genios (ğunūn), el mağgūub comete idolatría menor (al-šrik al-asgar), otorgando un poder que no tiene comparación con el de Allāh.

Por eso, este mundo está vedado a gente con una dilatada experiencia en asuntos esotéricos y unos dones concretos. El šayh que se ocupe de estos asuntos debe ser alguien, según me explicaban, de suma confianza y con gran conocimiento de la realidad esotérica. Preguntando por referencias sobre esta clase de especialistas, mientras estuve en Kaolack (Senegal), varias personas me hablaron de un brillante maestro pular, quien tenía una relación especial tanto con ángeles como con genios. Un hombre con un conocimiento extraordinario de lo evidente (zāhir) y de lo oculto (bätin), su nombre era Thierno Hassan Dem (1920-1989).

27 En uno de los textos clásicos del sufismo contemporáneo 'Abdal'azīz al-Dabbāgh menciona: « (...) [Los mağādīb] no son admitidos en el Diwān porque no tienen libertad en poder espiritual ( $t a^{-}$ sarruf). Si se les otorga poder espiritual, el común de las personas perecerían» cit. en Ahmad b. alMubārak al-Lamțī, al-dahab al-ibrīz min kalām sayyidi 'Abdal'azīz al-Dabbāgh [Pure gold from the words of sayyidi 'Abdal'azizz al-Dabbāgh]. Ed. y trad. Bernd Radtke y John O'Kane. Brill, Leiden, 2007, p. 595. Y a mismo respecto, Ibrāhīm Niasse advierte que el mağdūb o raptado espiritualmente, no es capaz de volver de las presencias divinas y queda atrapado inconscientemente en ellas lo que se traduce en la tierra como un simple loco (mağnūn), un ciego ('amā) ante la realidad. La referencia se encuentra en una carta fechada en 1930 en su Ğawāhir al-rasā’il: «El motivo de este escrito es haceros saber que dos tipos de personas no tienen nada que hacer conmigo o en este camino [tarīqa]: los seducidos [mağdūb] y los que han interrumpido su búsqueda, un buscador [sālik] que no ha llegado a ser atraído [ğadab].» cit. Ibrāhīm Niasse, Ğawāhir al-rasā’’ll, Vol. 1., Shaykh Aḥmad Abū l-Fatḥ b. 'Alī, Kano, 2013, p. 7. 


\section{EL MAESTRO, EL GENIO Y EL ÁNGEL}

Thierno Hassan Dem (1920-1989)28 fue uno de los nombres clave para la fayda en la comunidad pular. Nacido al norte de Senegal, en Futa Tooro, estudió de forma tradicional y tras la muerte de su šayh encontró a Ibrāhīm Niasse. Dem vio a Niasse en un sueño y se apresuró a conocerle, su šayh - ya fallecido - le dijo que no tendría un maestro mejor que šayh Ibrāhīm. A partir de ese momento, el año 1947, Dem se convirtió en un fiel discípulo y se entregó a sus quehaceres educativos y gnósticos. ${ }^{29}$ Con gran autoridad dentro de la tariqa Tiğāniyya, escribió varias obras muy importantes para la tarīqa como fueron Kašf al-gita $\overrightarrow{\text {, }}$, Nūr al-kamāl, o el importante comentario (šarh) del poema del šayh Muhammad Fāl: Miftāh al-wusūl ilā hadrat al-rasūl.

Es un autor que debería ser reconsiderado y estudiado en profundidad debido a su enorme calidad intelectual y a sus profundas experiencias gnósticas, muy importantes para el neosufismo contemporáneo. Dem era bien conocido por sus enormes habilidades esotéricas. En Medina Baye, la ciudad de Niasse, circula, de forma privada, una copia de su cuaderno de secreto (kunnāš al-asrār) con cientos de secretos suyos y heredados de la tradición pular.

Yo conseguí una copia de este kunnā̌ $̌$ en forma de manuscrito de mercado en junio de 2014, durante mi primer trabajo de campo en Senegal. El libro es de gran valor pues contiene información muy interesante sobre la doctrina esotérica de la comunidad pular. Como ya explicaba, la autoría de este kunnaš no es solo de Dem, sino que se trata de una obra intertextual

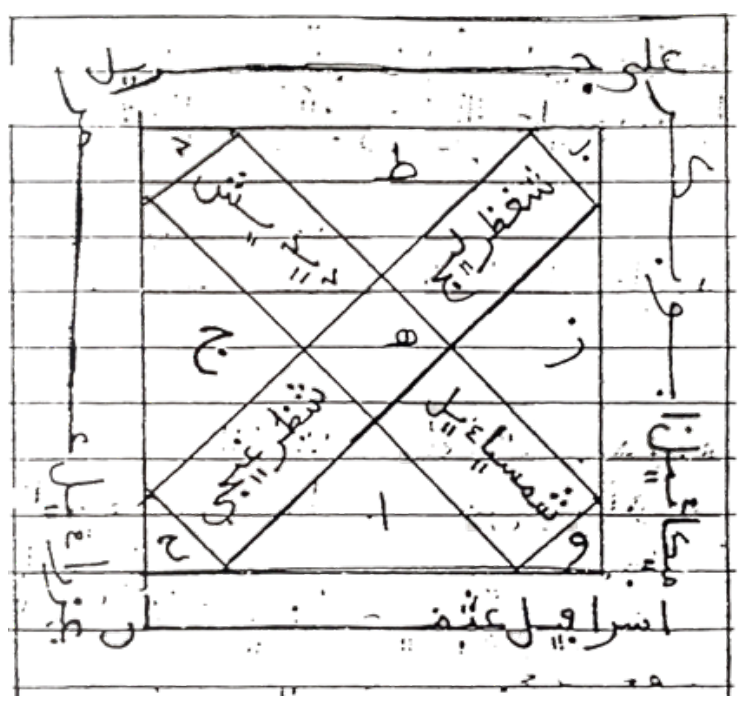

y polifónica, de herencias y que representa muy bien el espíritu intelectual del Sahel.

De este kunnā̌s, para ilustrar este texto, he elegido un ejemplo de tecnología de protección de tradición pular. Se trata de un hatm almalā’ika (sello de los ángeles), un talismán (tilasm) usual en estos libros de los cuales yo conocía varias versiones. En concreto esta versión (figura 1) es un talismán que relaciona los nombres de los principales ángeles con los califas del Profeta Muhammad.

Fig. 1. Hatm al- malä'ika. Kunnāš alasrār, Medina Baye, s.a.

28 ALA IV: 2004, pp. 306-307

29 Véase su obra autobiográfica en árabe Masīñ ilā saay̧ al-Islām Ibrāhàm Niasse, s.n., 1980. 
La figura se compone de un sello cuadrangular en forma de equis con nombres de poder de Allāh (ism al-ğalā $l$ ). El sello se remata con unas letras con valor numérico (abğad) que esconde un cuadrado mágico de tres filas (budüh) horizontales y verticales. Al resolver las letras quedaría el siguiente cuadrado mágico:

\begin{tabular}{|l|l|l|}
\hline 4 & 9 & 2 \\
s & $b$ & $u$ \\
\hline 3 & 5 & 7 \\
$\tau$ & 0 & $j$ \\
\hline 8 & 1 & 6 \\
$\tau$ & 1 & 9 \\
\hline
\end{tabular}

Aquí nos encontramos frente a la parte más esotérica e inaccesible del texto, codificada y sólo apta para iniciados. En sí, este compone el mecanismo principal de protección porque corresponde la invocación codificada y su posterior ejecución ritual. La transmisión del secreto (sirr), para poder activarlo, supone una iniciación que solo otorga el say h al discípulo y supone el momento central de la fase de educación gnóstica (tarbiya) ${ }^{30}$

A su vez, el cuadrado delimita un marco realizado por los nombres de los principales ángeles y los califas del Profeta orientados según los puntos cardinales como suele ser usual. Así se lee en el sello (figura 1): (al norte) 'Alī | Ğibrīi; (al sur) Isrāfil | 'Utmān; (al este) Azrā'îl | 'Umar; (al oeste) Mikā'îl | Abū Bakr.

La lectura simbólica que sacamos de este talismán es cuanto menos interesante. La petición, codificada en abğad, es protegida por los nombres de ángeles y califas, que actúan de forma arquetípica resaltando atributos. 1) Ǵibril que es, etimológicamente, «la fortaleza de Dios» y, además, su heraldo se relaciona con 'Alī. Así, se realza el rol de yerno favorito y protegido del Profeta, su califa esotérico. 2) Isrāfil al que a menudo se le atribuye la manifestación de la belleza y la poesía se relaciona 'Utman encargado del orden interno y quien ordenó escribir el Corán. 3) Azrāîil, el ángel de la muerte, es el encargado de guiar a un mundo nuevo (el paraíso) se relaciona con Umar que fue el responsable de la gran expansión del islam. 4) Mikā'îl, tradicionalmente el ángel que rechaza a los enemigos de la creencia, se relaciona 
con Abū Bakr y con su primera actitud de mantener justicia en la primera comunidad tras la muerte del Profeta. ${ }^{31}$

Estas analogías personifican un binomio, cuasi arquetipal, entre los propios ángeles y los califas, actuando en dos niveles simbólicos el plano celeste y el plano terrestre. En el plano celeste estos ángeles actúan con misiones específicas mandadas por Allāh, mientras que en el plano terrestre los califas actúan igualmente bajo órdenes del Profeta Muhammad. La idea de incluirlo en el talismán viene a responder a esa dualidad y actuar no solo en la tierra o en el cielo, al ser un útil de protección, sino también en los mundos mediales. Así se cubren todos los posibles mundos o planos (hadra) de acuerdo a la cosmología sufí. De modo que nada ni nadie pueda escaparse - como indica la cita coránica- de la faz de Allāh. ${ }^{32}$

El talismán que presenta Dem en su kunnāš es mucho más que un dispositivo de poder inmediato como podría parecer. Simbólicamente, como he intentado mostrar, encierra una representación cosmológica total, tanto espacial como temporal, en el que se manifiestan los diferentes niveles esotéricos. Con el objetivo de actuar, a través del mensaje que contiene en su interior, en todos ellos. Y, de hecho, son los ángeles, esa luz que fluye interplanos, la que actúa de garantes del orden del universo a mandato del Señor $(r a b b)$. Como vemos esta pequeña representación gráfica esconde muchas más cosas de las que podría parecer a priori.

Otra historia que circula en Senegal sobre Dem - y que yo he podido recoger- es que a él se le atribuía la capacidad de enseñar a los genios (ğunūn) Corán, fiqh (jurisprudencia islámica) o sufismo. La tradición dice que muchos de estos genios alumnos suyos se hicieron tiǧāni. La narración oral que recogí en Kaolack de uno de mis informantes dice así:

«Thierno ${ }^{33}$ Hassan Dem era un hombre del visto y del no visto. Uno de sus prodigios fue enseñar a los genios que vivían en el Salum. Para él no era un prodigio, era algo normal. Los genios conviven con nosotros y comparten con nosotros. Porque hay de todo, los hay musulmanes y los hay kāfir. Son como nosotros. Thierno se sentaba cerca de un baobab, con té y aunque para muchos estaba vacío, otros los veían [a los genios]. Y aprendían el Corán como lo hacen los niños hasta convertirse en karamoko34, y también aprendían fiqh y se hacían alfas35. Thierno enseñaba con la misma paciencia que lo

31 Notas de trabajo de campo en Kaolack, Senegal, julio de 2016.

32 Corán, 2: 115.

33 Nombre tradicional en idioma pular para los maestros coránicos.

34 En idioma pular profesor de Corán.

35 En el entorno de África Occidental un alfa es una abreviatura de al-faqīh, un experto en fiqh y 
hacia a los hombres. Los genios lo comprendían y algunos se hicieron tiğāni. El šayh Baye [Ibrāhīm Niasse] y el hātim [šayh Tiğānī] estaban contentos de ver como se expandía el camino del Profeta (saws) por toda la creación de Allāh $t a^{\varsigma} a \bar{a} \bar{a} \gg{ }^{36}$

Esta narración ha sido refrendada por familia directa de Ibrāhīm que, sin tal profusión de detalles, confirmaban la narración de mi informante. Y supone un testimonio curioso de la interacción entre genios y sufies en la contemporaneidad, y además sin un cariz negativo. Esto es algo interesante para la investigación ya que rompe dualidades y se acerca más a la visión que proponía, anteriormente, visto desde el sufismo tiğānī.

El carisma, además de las dotes esotéricas, de Dem propiciaba esta situación llegando al extremo de ser maestro de genios, posteriormente islamizándolos y convirtiéndolos en fervientes sufies. Este caso no es, ni mucho menos, único, pues en las narrativas populares hay otros casos interesantes como ocurría con la anteriormente relatada de al-Fūti Tāl. En este en cuestión, se enfatiza que para Dem no se trata de una acción espectacular o que merezca especial atención, forma parte de su rol de maestro.

Uno de los puntos más interesantes está en que mi informante gradúa las acciones y las enmarca dentro de la estética narrativa concreta del mundo pular. El baobab, el té y la clase coránica encajan muy bien en el imaginario clásico del sabio pular. Cambiando los alumnos niños por genios, se realiza una labor de «contraprestación» universal que logra modular la idea hasta un interesante punto: la labor del šay h es universal. Esta tensión entre lo local y lo universal es bien común y corresponde, en última instancia, al modelo de islam expandido por el neo-sufismo, categoría a la que pertenece la Tiğāniyya. ${ }^{37}$ Por eso, los actos de Dem en la historia narrada tienen una carga simbólica muy importante, pues lo universal no solo se expande entre razas y países, sino entre los distintos planos de realidad.

La confluencia entre ángeles y genios en su sufismo es muy interesante y nos revela cuán viva están, a día de hoy, estas tradiciones en África occidental. Por otra parte, y desde un plano simbólico, la normalización de relaciones con estos seres señala el triunfo de la gnosis tiğānī frente a los discursos que las criminalizan por puro desconocimiento.

sinónimo de sabio islámico.

36 Notas de trabajo de campo en Kaolack, Senegal, julio de 2016.

37 Antonio de Diego González, Sufismo Negro, Córdoba, Almuzara, 2019, pp. 41-45. 


\section{A MODO DE GONGLUSIÓN: «DURANTE EL GAMINO Y EL ENGUENTRO ESTÁ LA "VERDADERA REALIDAD""}

Si no se entiende este trabajo dentro de la cosmovisión espiritual de África Occidental todo lo que se ha explicado se reduciría a una mera y vacía anécdota. Igualmente, lo mismo ocurre si no se comprende que estas angelologías y demonologías son, principalmente, vectores epistémicos para explicar la realidad desde lógicas locales. Lógicas locales que, a su vez, entienden estos fenómenos como reflejos más profundos de la realidad (haqiqqa).

El mundo pular, como otros tantos, ha guardado muchas de estas narrativas propias, desde un plano étnico, y las ha amalgamado con creencias que se insertan puramente en las tradiciones islámicas. El resultado es una cosmología, con una consiguiente angelología, fascinante donde África y el mundo semita se entrecruzan y comparten imaginarios que remiten a aspectos tanto profundos como cotidianos.

Por ejemplo, la «lucha simbólica entre la aurora y el ocaso» se manifiesta, igualmente, a un nivel macrocósmico (la naturaleza) y al mismo tiempo lo hace a un nivel microcósmico (el ser humano). Es un dar sentido a lo cotidiano a través de lo simbólico. Genios y ángeles no actúan -según el sufismo africano- sino como nosotros y el esfuerzo de verlos es un tránsito hacia comprender un absoluto. De ahí que las transformaciones naturales o el reflejo en la salud (enfermedades provocadas por genios, infertilidad, posesiones, etc.) sean los espejos de lo que ocurre en los mundos intermediales. Por eso, el šayh media entre mundos y con una actitud un tanto chamánica comprende realidades y ayuda a normalizar esas lógicas que a veces se vuelven disruptivas socialmente. Viaja a un aparente caos, que rebasa la lógica común, y ve que es otra realidad más, pero no la última.

El sufismo experimenta ese plano simbólico y ayuda a ver que es otro velo más en el camino al absoluto, pero que no por ello es menos importante. Esta actitud ayuda a «no cegarse con la luz de lo divino» ${ }^{38}$ para que el viaje del gnóstico ('ârif) sea progresivo. El velo es una paradoja pues es lastre cognoscitivo y, a la vez, protección. El viaje progresivo (sayr) a través de los mundos intermediales, y su posterior comprensión, ayuda a esta progresión de conocimiento de la verdadera realidad (haqq bi-l-haqq).

El encuentro del gnóstico ('ārif) y los seres intermediales según las narrativas suele ser posterior al viaje (sayr). Al haber rasgado (kašf) el sufí algunos de los velos existentes durante el viaje, el posterior encuentro ayuda a ser más escéptico ante los genios o a saber utilizar con sentido profundo los recursos que otorgan los ángeles. Ese escepticismo es el que hace no caer en una idolatría ante las habilidades de los seres intermediales.

38 Notas de trabajo de campo en Kaolack, Senegal, julio de 2016. 
Por eso, creo que es buen colofón para este texto ver como los ejemplos de Dem, tanto en el talismán como en la narración, indican esta actitud de normalidad ante los profundos reflejos de los mundos intermediales. Sus discípulos, según narraban, pudieron beneficiarse de la sabiduría y de las aperturas del maestro, que ayudó a muchos a obtener la gnosis divina (ma'rifa) y la correspondiente apertura espiritual (fath).

En esta misma línea, otro de mis informantes me decía con cierta autoridad: «El ser humano ostenta el califato de la creación y si se cultiva puede ver y controlar otros planos, siempre que Allāh lo quiera e imite a su Profeta (sawes)». ${ }^{39} \mathrm{Mi}$ informante insistía en que el poder del ser humano está en su capacidad de imitar al Profeta Muhammad, en seguir su sunna y, finalmente, en ver a través de su luz $(n \bar{u} r)$. La metáfora de la luz que, transformada en conocimiento, ilumina el camino hacia la aniquilación $(f a n \bar{a})$ de la consciencia en el absoluto ya sea humano hecho de barro, ángel hecho de luz o genio hecho de fuego. Al fin y al cabo, la anulación de las diferencias de la existencia en el uno primordial. Nada es lo que parece y menos en las lógicas del Sahel. Y así, el viajero (sālik) se plantea una paradójica pregunta mientras prosigue con su ascensión espiritual $(s a y r): ~ ¿ E s t a b a$ el šayh realmente rodeado de ángeles y genios? 